\title{
Severe manifestations of oculoauriculovertebral spectrum in a cocaine exposed infant
}

\author{
Mira Lessick, Rohitkumar Vasa, Jeannette Israel
}

Oculoauriculovertebral spectrum (OAV) is a causally heterogeneous developmental field defect characterised by variable combinations of facial, ear, eye, and vertebral anomalies, which may be accompanied by cardiac, central nervous system, and other visceral malformations. The disorder has a wide range of phenotypic expression, and right sided involvement is more common or more severe or both. We report a newborn with severe manifestations of this disorder who was exposed to cocaine prenatally. Oculoauriculovertebral spectrum in a cocaine exposed infant has not been previously reported.

A $2977 \mathrm{~g}$ black female was delivered at 38 weeks' gestation by caesarian section to a 24 year old, G2 mother with sickle cell trait. The mother used cocaine intranasally throughout pregnancy, but other illicit drug use was denied. The family history was negative. Apgar scores were 6 and 9 at one and five minutes, respectively. The baby required intubation shortly after birth for respiratory distress.

On examination the infant was noted to have cranial asymmetry, upward slanting palpebral fissures, hypotelorism, microphthalmia of the right eye, absent right ear and ostium, left preauricular skin tag, micrognathia, prominent right sided gum margin, high arched palate, neck webbing, preaxial polydactyly of the right hand, scoliosis, and hypoplasia of the right chest wall (fig 1). There was no heart murmur. Chest radiograph showed four absent right middle ribs, scoliosis with curvature to the right in the dorsal spine, and two hemivertebrae (fig

Section of Genetics and Department of MaternalChild Nursing, Rush-Presbyterian-St Luke's Medical Center, Chicago, Illinois, USA.

$M$ Lessick

Department of Pediatrics, Mercy Hospital and Medical Center, Stevenson Expressway at King Drive, Chicago, Illinois 60616-2477, USA.

R Vasa

Department of Pediatrics, Christ Hospital, Chicago, Illinois, USA.

J Israel

Correspondence to Dr Vasa.

Received for publication 19 February 1991.

Accepted for publication 15 March 1991.
2). Ultrasound of the head showed bilateral choroid plexus cysts, the right cyst measuring $3.6 \mathrm{~mm}$ and the left $4 \mathrm{~mm}$. Renal ultrasound showed an absent right kidney. Chromosomes were normal, and urine cocaine screen was positive. The placenta was normal.

$\mathrm{OAV}$ is a relatively common condition with an estimated frequency ranging from 1 per 5600 to 1 per 26550 births. ${ }^{12}$ While most cases are sporadic, familial occurrences have been reported. Chromosomal anomalies, such as del $(5 p)$, trisomy 18 , and $\operatorname{dup}(7 \mathrm{q})$ have also been observed. ${ }^{1}$ Besides craniofacial abnormalities, common features of OAV include skeletal and cardiac defects. Central nervous system, renal, pulmonary, laryngeal, and gastrointestinal anomalies may also occur. Our patient had severe physical abnormalities compatible with OAV as evidenced by facial, ear, and eye defects, and the

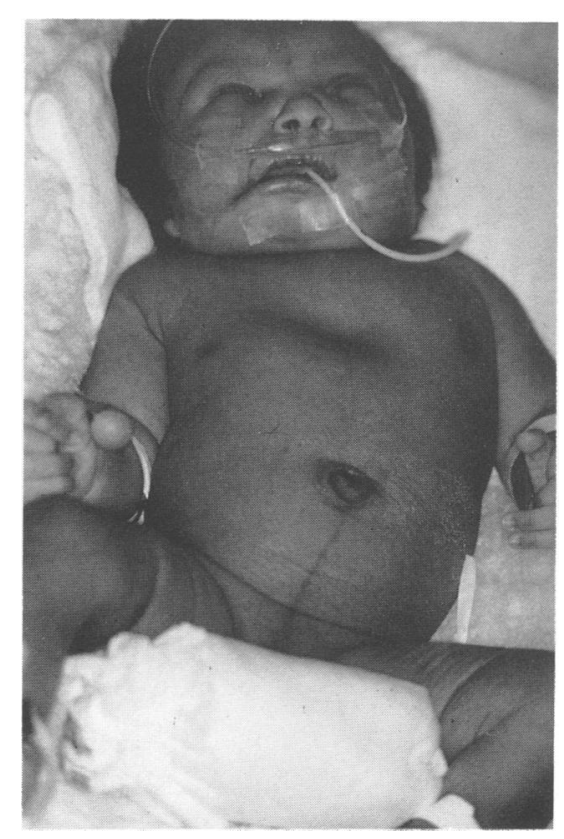

Figure 1 The external appearance of the infant. 


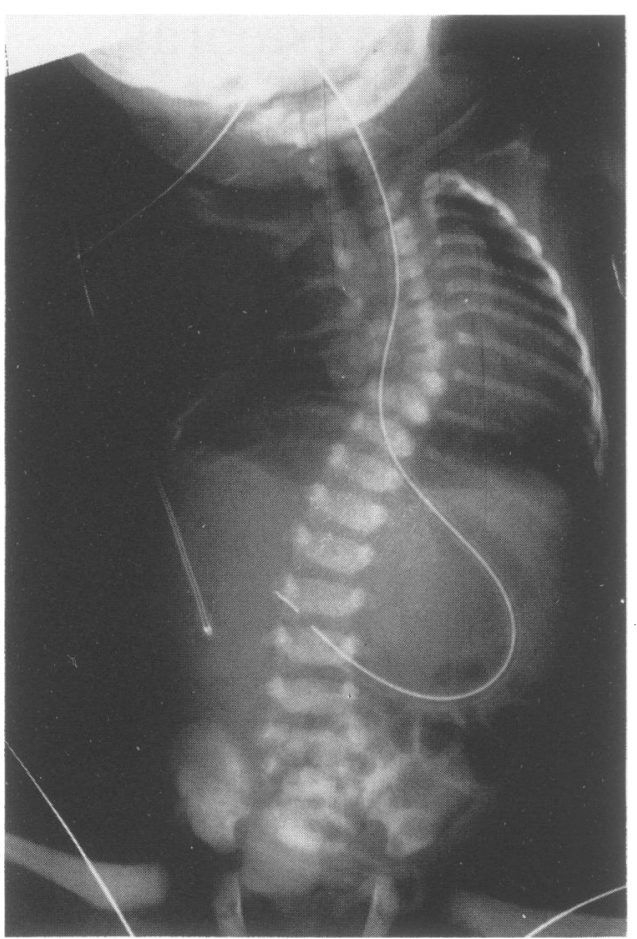

Figure 2 Radiograph of the infant showing skeletal anomalies. findings of absent kidney and ribs, scoliosis, hemivertebrae, neck webbing, choroid plexus cysts, and polydactyly. Her major malformations primarily involved the right side.

The occurrence of multiple anomalies with prenatal cocaine exposure may have been coincidental in this case. However, several teratogenic agents, including thalidomide, primidone, and retinoic acid, have been implicated in cases of OAV. ${ }^{1}$ Vascular disruption is also thought to be one possible mechanism for the pathogenesis of this disorder. ${ }^{1}$ Further, a spectrum of defects (central nervous system, renal, limb, gastrointestinal) associated with embryonic and fetal vascular disruption accompanying maternal cocaine abuse has been documented. ${ }^{3}$ We hypothesise that the effects of cocaine could have resulted in vascular disruption, leading to, or perhaps potentiating, the clinical features of OAV in this infant. While more cases are needed to confirm this hypothesis, clinicians should be alert to the possible complication of OAV spectrum in infants exposed to cocaine prenatally.

1 Cohen MM, Rollnick BR, Kaye CI. Oculoauriculovertebral spectrum: an updated critique. Cleft Palate $\mathcal{F}$ 1989;26:276-86.

2 Rollnick BR, Kaye CI, Nagatoshi K, Hauck W, Martin AO. Oculoauriculovertebral dysplasia and variants: phenotypic characteristics of 294 patients. Am $\mathcal{F}$ Med Genet 1987; 26:361-75.

3 Hoyme HE, Jones KL, Dixon SD, et al. Prenatal cocaine exposure and fetal vascular disruption. Pediatrics 1990; 85:743-7. 